\title{
Effect of On-Pump CABG (Roller Versus Centrifugal Systems) on MCP-1, TNF- sR and IL6 Behaviour
}

Renato Braulio ${ }^{1^{*}}$, Marcelo Dias Sanches ${ }^{2}$, Antonio Lúcio Teixeira Junior ${ }^{3}$, Mauro Martins Teixeira ${ }^{4}$, Paulo Henrique Nogueira Costa ${ }^{1}$, Antonio Luiz Pinho Ribeiro $^{3}$, Claudia Alves Couto ${ }^{3}$ and Claudio Léo Gelape ${ }^{2}$

${ }^{1}$ Federal University of Minas Gerais, School of Medicine, Division of Cardiology and Cardiovascular Surgery, Belo Horizonte, MG, Brazil

${ }^{2}$ Federal University of Minas Gerais, School of Medicine, Department of Surgery, Belo Horizonte, MG, Brazil

${ }^{3}$ Federal University of Minas Gerais, School of Medicine, Department of Internal Medicine, Belo Horizonte, MG, Brazil

${ }^{4}$ Federal University of Minas Gerais, School of Medicine, Department of Biochemistry and Immunology, Belo Horizonte, MG, Brazil

*Corresponding author: Renato Braulio, Av. Alfredo Balena 110, 5th floor - Department of Cardiology and Cardiovascular Surgery, Neighborhood: Santa Efigenia, Cep : 30130-100, Belo Horizonte, MG, Brazil, Tel: +55 31 34099437; E-mail: clgelape@uol.com.br

Received November 02, 2014; Accepted December 22, 2014; Published December 27, 2014

Copyright: (c) 2015 Braulio R, et al. This is an open-access article distributed under the terms of the Creative Commons Attribution License, which permits unrestricted use, distribution, and reproduction in any medium, provided the original author and source are credited

\begin{abstract}
Background

We aimed to evaluate the cytokines monocyte chemotactic protein 1 (MCP-1), TNF soluble receptor (TNF-sR1) and interleukin 6 (IL-6) behavior in patients submitted to CABG (coronary artery bypass grafting) surgeries comparing roller to centrifugal extracorporeal circulation (ECC) pumping systems.

\section{Methods}

We randomized prospectively 43 adults who had elective on-pump CABG with the use of a roller (group I; $n=22$ ) or a centrifugal system (group II; $n=21$ ). Plasma levels of MCP-1, TNF-sR1 and IL-6 were determined by Elisa before the induction of anaesthesia (T1), $35 \mathrm{~min}$ after initiation of ECC (T2), $1 \mathrm{~min}$ after aortic declamping (T3), and 2,6 and $24 \mathrm{~h}$ after the operation (T4, T5 and T6, respectively). The two groups were matched according to preoperative features. The groups I and II showed similar perioperative characteristics and clinical postoperative outcomes. The plasma levels of MCP-1 and TNF-sR1 reached a peak at T4 and T5 in both groups. MCP-1 in group I was significantly higher $(P=0.020)$ than in group II at T5, while plasma levels of TNF-sR1 in group I were significantly $(P=0.028)$ higher than in group II at T4. In both groups, the levels of IL-6 reached a peak at T5. Group I showed higher IL-6 plasma levels $(P=0.006)$.
\end{abstract}

\section{Conclusion}

We conclude that both roller and centrifugal pumps induce inflammatory responses to on-pump CABG procedures but higher levels of MCP-1, TNF-sR and IL6 were verified using roller systems.

Keywords: Cardiopulmonary bypass; Inflammatory response; Myocardial revascularization; Roller and centrifugal pumps; Inflammatory cytokines

\section{Introduction}

Cardiac surgery involving extracorporeal circulation (ECC) has been related to different extent of systemic inflammatory response (IR) resulting in patient's morbidity and mortality [1]. The contact of blood with the non-endothelial surfaces of the ECC components induces a cascade of inflammatory reactions associated with increased levels of cytokines, such as interleukin-1 (IL-1), IL-6, IL-8 and the tumour necrosis factor (TNF) [1-3].

Many factors can influence the emergence of IR in patients submitted to on-pump CABG (coronary artery bypass grafting), including type of propelling system (roller or centrifugal), manipulations of the coagulation system, the ischemia interval and injury from reperfusion, the degree of hypothermia, the type of prime- circuit, the amount of gas exchanged by the oxygenators, and the pericardial blood suction [4]. Circulation of blood through ECC, which is necessary in many types of cardiac surgery, relies on two main types of propelling systems, namely, roller and centrifugal pumps. Roller pumps propel the fluid in a continuous flow through compression by rigid rollers of a flexible plastic tube held in a circular raceway. Centrifugal pumps comprise an impeller, driven by an electromagnetic mechanism, which propels the blood by creating pressure differences within the fluid. Even though the types of pumps have been associated to inflammatory response and clinical outcomes, results are contradictory and both systems are currently used $[5,6]$.

A large range of inflammatory mediators has been examined after CABG. However there is little agreement as to witch inflammatory mediator is most predictive of IR, the development of organ dysfunction, or which one is important clinically after surgery. Identifying a common link to the generation of IR is important and may allow future therapies. New evidence suggests that monocyte chemotactic protein 1 (MCP-1) could be a key mediator in 
inflammatory process and a new target for the treatment of inflammatory diseases [7]. IL-6 and TNF soluble receptor (TNF-sR1) are well known inflammatory mediators. The aim of the present study was to investigate levels and behaviour of cytokines MCP-1, IL-6 and TNF-sR1 during on-pump CABG using roller and centrifugal pumps.

\section{Patients and Methods}

\section{Ethical issues}

The project was approved by the local Ethical Research Committee. Written informed consent was obtained from all participants prior to the study.

\section{Patients}

Potential participants were selected at the outpatient clinic of the Hospital. The inclusion criteria were: age $>18$ years, surgical indication for elective on-pump CABG based in international criteria, first-time cardiac surgery, ventricular ejection fraction $>30 \%$ [3]. Exclusion criteria were: unstable angina, chronic obstructive pulmonary disease, active endocarditis and critical preoperative conditions. A total of 43 patients met the inclusion criteria.

The present study was conducted prospectively and the patients were assigned consecutively and randomised to procedures employing a roller pump (group I - on-pump roller CABG; $\mathrm{n}=22$ ) or a centrifugal pump (group II - on-pump centrifugal CABG; $n=21$ ) for ECC according to the order of presentation for surgery. On the day allocated for the operation, the patient was admitted to the hospital and submitted to anamnesis, physical examination and operative risk assessment according to the guidelines of the European System for Cardiac Operative Risk Evaluation (EuroSCORE) [8]. All operations were performed by the same surgical team and the same group of anaesthesiologists and perfusionists.

\section{Anaesthesia}

Balanced general anaesthesia was applied through intravenous injection of midazolam ( 0.1 to $0.3 \mathrm{mg} / \mathrm{kg}$ ), fentanyl citrate (5 to 10 $\mu \mathrm{g} / \mathrm{kg}$ ) and etomidate $(0.15$ to $0.30 \mathrm{mg} / \mathrm{kg})$, with pancuronium bromide $(0.1 \mathrm{mg} / \mathrm{kg})$ as muscle relaxant. Anaesthesia was maintained with fractionated intravenous doses of fentanyl citrate (5 to $10 \mu \mathrm{g} / \mathrm{kg}$ ) and inhaled isoflurane ( 0.5 to $1.0 \%$ minimum alveolar concentration).

No antifibrinolytic or anti-inflammatory agents were employed during the surgery. Antibiotic prophylaxis of the surgical site was performed using intravenous injections of cefazolin $(2 \mathrm{~g}$ every $2 \mathrm{~h}$ during the operation and every $8 \mathrm{~h}$ during the first $24 \mathrm{~h}$ after the operation).

\section{Surgical procedure}

The following procedures were performed subsequently: placement of sterile drapes, median sternotomy, intravenous systemic heparinization $(400 \mathrm{IU} / \mathrm{kg})$, insertion of cannulas in the aorta and right atrium, introduction of cardioplegia cannula in the aortic root, initiation of ECC and aortic clamping. Intermittent antegrade cold blood cardioplegia for cardioprotection was performed by infusion of cold $\left(4^{\circ} \mathrm{C}\right)$ St. Thomas' Hospital cardioplegic solution into the coronary circulation every $20 \mathrm{~min}$ associated with passive hypothermia around $32^{\circ} \mathrm{C}$. Myocardial revascularization was achieved by grafting the left internal thoracic artery to the left anterior descending artery and grafting the saphena magna vein to other coronary arteries. After completion of the coronary anastomoses, the aortic clamp was released, the patient was warmed systemically to $36.5^{\circ} \mathrm{C}$, the ECC circuit was disconnected and the cannulas were removed. In order to counteract the anticoagulant effects of heparin, protamine sulphate $(10 \mathrm{mg} / 1000 \mathrm{IU}$ heparin) was administered by slow intravenous injection.

\section{The ECC circuit}

All procedures were carried out using the same ECC circuit comprising a microporous polypropylene membrane oxygenator (Trillium Affinity; Medtronic Minneapolis, MN, USA) with integrated venous cardiotomy reservoir and a heat exchanger connected with polyvinylchloride tubing (Comex, Belo Horizonte, Brazil). The ECC circuit was primed with $800 \mathrm{~mL}$ of $0.9 \%$ sodium chloride solution. An ALC $310^{\circ}$ roller pump (Alcard Indústria Mecânica, Sorin Group, São Paulo, Brazil) or a centrifugal IBC FloPump with Medtronic Bio-Medicus Bio Console (International Biophysics Corporation, Austin, USA) were used to propel blood through the ECC circuit with a targeted pulsatile flow of $2.4 \mathrm{~L} / \mathrm{min} / \mathrm{m}^{2}$, mean arterial pressure of 60 to $70 \mathrm{~mm} \mathrm{Hg}$ and haemodilution with haematocrit of 20 to $30 \%$. The partial pressure of oxygen in the arterial blood was maintained close to $250 \mathrm{~mm} \mathrm{Hg}$, the initial fraction of inspired oxygen was $50 \%$, activated clotting time was $480 \mathrm{~s}$ and venous drainage was gravity dependent. The same catheter employed in cardioplegia was used for aspiration of the aortic root (vent). After systemic heparinization, intrapericardial blood was aspirated and returned to the patient. A negligible volume of blood entered the pleural cavity but was not returned to the patient.

\section{Quantitative analysis of cytokines}

Peripheral blood samples $(3 \mathrm{~mL})$ were obtained from the radial artery immediately before the induction of anaesthesia (T1), $35 \mathrm{~min}$ after initiation of ECC (T2), 1 min after release of the aortic clamp (T3), and 2, 6 and $24 \mathrm{~h}$ after surgery (T4, T5 and T6, respectively), and placed into heparinized sterile tubes (Becton \& Dickinson, Franklin Lakes, NJ, USA). Plasma was separated by centrifugation at $3000 \mathrm{rpm}$ for $10 \mathrm{~min}$ and stored in the freezer at $-80^{\circ} \mathrm{C}$ until required for analysis. Concentrations of MCP-1, TNF-sR1 and IL-6 in plasma samples were determined using commercial sandwich enzyme-linked immunosorbent assay (ELISA) kits (R\&D Systems ${ }^{\circ}$, Minneapolis, MN, USA) according to the manufacturer's instructions.

\section{Statistical analysis}

Descriptive statistics of the data were expressed as minimum, maximum, mean \pm standard deviations (SD) and median values. Data relating to IL-6 concentration were not normally distributed and, therefore, the non-parametric Mann-Whitney $U$ test was used to compare median values between the two groups and the nonparametric Friedman test was used to detect within-group differences relating to time of sampling (T1 - T6). Categorical variables relating to groups I and II were compared using the $\chi^{2}$ test, but in situations in which this test could not be applied (i.e. expected values $<5$ ) the Fisher exact test was employed. In all tests, the differences between the two groups of data were considered statistically significant at $\mathrm{P}<0.05$. 
Citation: Braulio R, Sanches MD, Teixeira Junior AL, Teixeira MM, Costa PHN, et al. (2015) Effect of On-Pump CABG (Roller Versus Centrifugal Systems) on MCP-1, TNF-sR and IL6 Behaviour . J Cardiovasc Dis Diagn 3: 186. doi:10.4172/2329-9517.1000186

Page 3 of 6

\section{Results}

Patients' preoperative, perioperative features and clinical postoperative outcomes are shown on Tables 1 and 2. No significant differences between patients of groups I and II were shown.

\begin{tabular}{|c|c|c|c|}
\hline Variable & $\begin{array}{l}\text { Group I }(\mathrm{N}= \\
22)\end{array}$ & Group II (N = 21) & $\mathbf{P}$ \\
\hline Age (years; mean $\pm S D^{a}$ ) & $60.6 \pm 12.0$ & $60.4 \pm 8.6(61)$ & 0.884 \\
\hline Weight $(\mathrm{kg}$; mean $\pm \mathrm{SD}$ ) & $69.2 \pm 13.3$ & $69.0 \pm 15.6(70.0)$ & 0.942 \\
\hline Cardiac risk $^{\mathrm{b}}($ mean $\pm \mathrm{SD})$ & $2.9 \pm 2.1$ & $1.9 \pm 1.7(2.0)$ & 0.145 \\
\hline Ejection fraction ${ }^{\mathrm{C}}($ mean $\pm \mathrm{SD})$ & $46.1 \pm 10.0$ & $55.1 \pm 15.9(57.0)$ & 0.257 \\
\hline Male/female ratio & $16 / 6$ & $19 / 2$ & 0.24 \\
\hline $\begin{array}{l}\text { Systemic arterial hypertension [n } \\
(\%)]\end{array}$ & $21(95.5)$ & $21(100.0)$ & 1 \\
\hline Diabetes mellitus [n (\%)] & $3(13.6)$ & $8(38.1)$ & 0.066 \\
\hline Peripheral arterial insufficiency & $1(4.5)$ & $3(14.3)$ & 0.345 \\
\hline Dyslipidemia [n (\%)] & $14(63,6)$ & $18(85.7)$ & 0.097 \\
\hline Smoking habit [n (\%)] & $12(54.5)$ & $15(71.4)$ & 0,252 \\
\hline Use of beta-blockers [n (\%)] & $20(90.9)$ & $14(66.7)$ & 0.069 \\
\hline Use of $A C E^{d}$ inhibitor [n (\%)] & $12(54.5)$ & $11(52.4)$ & 0.887 \\
\hline Use of acetylsalicylic acid [n (\%)] & $14(63.6)$ & $8(38.1)$ & 0.094 \\
\hline Use of statins [n (\%)] & $12(54.5)$ & $16(76.2)$ & 0.203 \\
\hline Severe heart failure ${ }^{\mathrm{e}}[\mathrm{n}(\%)]$ & $5(22.7)$ & $4(19.0)$ & 1 \\
\hline
\end{tabular}

aStandard deviation.

${ }^{b}$ According to the European System for Cardiac Risk Evaluation (EuroSCORE). CInformation not available for some patients, namely, 15 in group I and 10 in group II.

dAngiotensin-converting-enzyme inhibitor.

eAccording to the New York Heart Association (NYHA). Differences between groups were considered statistically significant at $\mathrm{P}<0.05$.

Table 1: Preoperative features of patients group I (on-pump roller $\mathrm{CABG}$ ) and group II (on-pump centrifugal CABG).

\begin{tabular}{|l|l|l|l|}
\hline Variable & $\begin{array}{l}\text { Group I } \\
\mathbf{( N = 2 2 )}\end{array}$ & $\begin{array}{l}\text { Group II } \\
(\mathbf{N}=\mathbf{2 1})\end{array}$ & $\mathbf{P}$ \\
\hline Perioperative characteristics: & & & 0.986 \\
\hline $\begin{array}{l}\text { Activated clotting time (min; } \\
\text { mean } \pm \text { SD })\end{array}$ & $768 \pm 117.7$ & $767 \pm 103.2$ & 0.599 \\
\hline $\begin{array}{l}\text { Operative time (min; mean } \pm \\
\text { SDa) }\end{array}$ & $158.2 \pm 30.0$ & $163.6 \pm 26.7$ & 0.435 \\
\hline $\begin{array}{l}\text { Extracorporeal circulation time } \\
\text { (min; mean } \pm \text { SD })\end{array}$ & $59.4 \pm 15.2$ & $62.6 \pm 17.1$ & 0.408 \\
\hline $\begin{array}{l}\text { Aortic cross-clamp time (min; } \\
\text { mean } \pm \text { SD })\end{array}$ & $44.2 \pm 13.8$ & $48.0 \pm 12.3$ & 0.142 \\
\hline Number of grafts (median) & 2 & 3 & 0.188 \\
\hline Blood transfusion [n (\%)] & $4(18.1)$ & $2(9.5)$ & \\
\hline
\end{tabular}

\begin{tabular}{|c|c|c|c|}
\hline $\begin{array}{l}\text { Administration of dobutamine [n } \\
(\%)]\end{array}$ & $17(77.3)$ & $16(76.2)$ & 1 \\
\hline $\begin{array}{l}\text { Administration of noradrenalin [n } \\
(\%)]\end{array}$ & $0(0.0)$ & $1(4.8)$ & 0.488 \\
\hline \multicolumn{4}{|l|}{ Postoperative characteristics: } \\
\hline $\begin{array}{l}\text { Intensive care time }[\mathrm{h} \text {; mean } \pm \\
\text { SD (median)] }\end{array}$ & $\begin{array}{l}140.7 \pm 260.2 \\
(48.0)\end{array}$ & $60.1 \pm 38.5(48.0)$ & 0.717 \\
\hline $\begin{array}{l}\text { Reoperation (bleeding) } \\
{[\mathrm{n}(\%)]}\end{array}$ & 2 (9.1) & $0(0.0)$ & 0.488 \\
\hline $\begin{array}{l}\text { Occurrence of hypotension }{ }^{b} \text { [n } \\
(\%)]\end{array}$ & $6(27.3)$ & $3(14.3)$ & 0.457 \\
\hline Use of noradrenalin [n (\%)] & $9(40.9)$ & $11(52.4)$ & 0.451 \\
\hline Use of dobutamine [n (\%)] & $15(68.2)$ & $11(52.4)$ & 0.289 \\
\hline $\begin{array}{l}\text { Occurrence of mediastinitis [n } \\
(\%)]\end{array}$ & $1(4.5)$ & $0(0.0)$ & 1 \\
\hline $\begin{array}{l}\text { Occurrence of sepsis } \\
{[n(\%)]}\end{array}$ & $4(18.2)$ & $0(0.0)$ & 0.108 \\
\hline $\begin{array}{l}\text { Occurrence of death } \\
{[\mathrm{n}(\%)]}\end{array}$ & $2(9.1)$ & $0(0.0)$ & 0.488 \\
\hline
\end{tabular}

Table 2: Perioperative and Postoperative features of patients of group I (on-pump roller CABG) and group II (on-pump centrifugal CABG).

\begin{tabular}{|l|l|l|l|l|l|}
\hline \multirow{2}{*}{$\begin{array}{l}\text { Time of } \\
\text { sampling }\end{array}$} & \multicolumn{2}{l}{ Group I (pg/mL) } & \multicolumn{2}{l|}{ Group I (pg/mL) } & P value \\
\cline { 2 - 6 } & Mean \pm SD $^{\mathrm{a}}$ & CV $^{\mathrm{b}}$ & Mean \pm SD $^{\mathrm{a}}$ & CV $^{\mathrm{b}}$ & \\
\hline T1 & $271.4 \pm 79.9$ & 29.4 & $465.3 \pm 283.7$ & 60.9 & $\mathrm{p}>0.05$ \\
\hline T2 & $460.6 \pm 252.2$ & 54.7 & $435.7 \pm 171.5$ & 39.3 & $\mathrm{p}>0.05$ \\
\hline T3 & $797.8 \pm 424.9$ & 53.2 & $941.1 \pm 495.6$ & 52.6 & $\mathrm{p}>0.05$ \\
\hline T4 & $4078.8 \pm 4138.4$ & 101.4 & $2340.0 \pm 2241.1$ & 95.7 & 0.096 \\
\hline T5 & $3863.2 \pm 4323.5$ & 111.9 & $1488.8 \pm 1257.6$ & 84.4 & $0.020^{*}$ \\
\hline T6 & $592.6 \pm 899.8$ & 151.8 & $502.4 \pm 141.4$ & 28.1 & $p>0.05$ \\
\hline T4 - T1 & $3807.4 \pm 4145.5$ & & $1874.6 \pm 2212.4$ & & 0.159 \\
\hline T5 - T1 & $3591.7 \pm 4327.1$ & & $1023.4 \pm 1369.0$ & & $0.035^{*}$ \\
\hline aStandard deviation, ${ }^{\mathrm{b}}$ Coefficient of variation, ${ }^{*}$ Significant concentrations \\
\hline
\end{tabular}

Table 3: Concentrations of MCP-1 in plasma samples from patients of group I (on-pump roller CABG) and group II (on-pump centrifugal CABG).

The plasma levels of MCP-1, TNF-sR1 and IL-6 from groups I and II at times T1 to T6 are shown in Figure 1 and Tables 3, 4 and 5 respectively. The between-group differences in plasma MCP-1 concentrations were statistically significant at $\mathrm{T} 5(\mathrm{P}=0.020)$. In group I, plasma levels of $\mathrm{MCP}-1$ at $\mathrm{T} 4$ and $\mathrm{T} 5$ were equivalent and significantly higher than those at T1, T2, T3 and T6, while in group II, the mean concentration of MCP-1 measured at T4 was significantly 
Citation: Braulio R, Sanches MD, Teixeira Junior AL, Teixeira MM, Costa PHN, et al. (2015) Effect of On-Pump CABG (Roller Versus Centrifugal Systems) on MCP-1, TNF-sR and IL6 Behaviour . J Cardiovasc Dis Diagn 3: 186. doi:10.4172/2329-9517.1000186

Page 4 of 6

higher than those at T1, T2, T3 and T6, while the concentration at T5 was similar to that at $\mathrm{T} 3$ but higher than those at $\mathrm{T} 1, \mathrm{~T} 2$ and $\mathrm{T} 6$ (Table 3 and Figure 1A). The levels of MCP-1 in both groups varied significantly according to the time of sampling $(\mathrm{P}=0.0001)$.

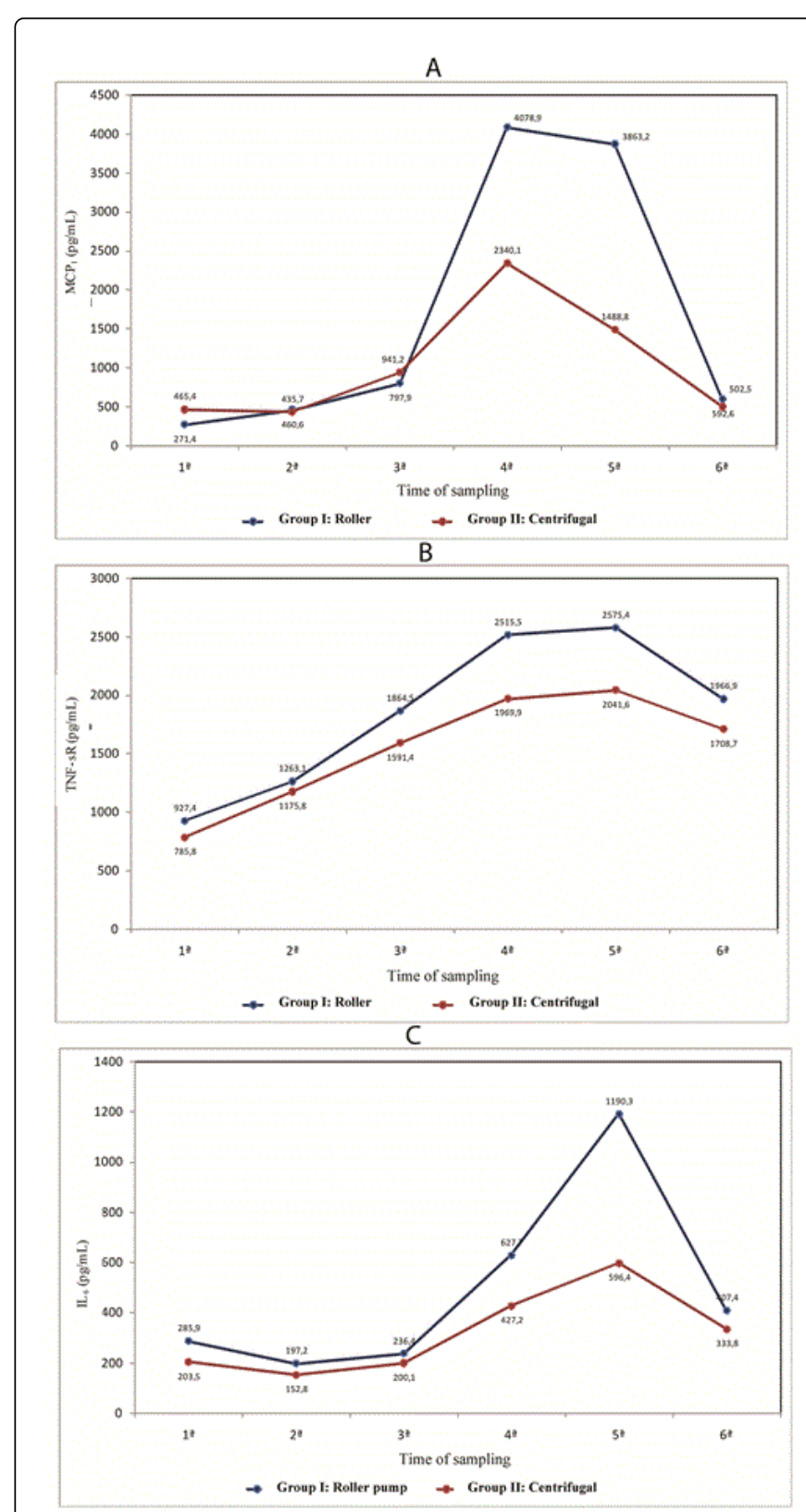

Figure 1: Variation in the concentration of monocyte chemotactic protein 1 (MCP-1; A), tumour necrosis factor soluble receptor (TNF-sR; B) and interleukin 6 (IL-6; C) in patients on-pump roller CABG (group I; ) or on-pump centrifugal CABG (group II; ) according to time: before the induction of anaesthesia (T1), $35 \mathrm{~min}$ after initiation of ECC (T2), 1 min after aortic declamping (T3), and 2, 6 and $24 \mathrm{~h}$ after surgery (T4, T5 and T6, respectively).

Assays of TNF-sR $R_{1}$ in patients of groups I and II revealed that plasma concentrations of the cytokine receptor increased significantly with time of sampling up to T4, following which they remained stable at T5 and declined at T6 to the levels found at T3 (Table 4 and Figure 1B). The between-group differences in plasma TNF-sR concentrations were statistically significant only at $\mathrm{T} 4(\mathrm{P}=0.028)$.

\begin{tabular}{|l|l|l|l|l|l|}
\hline \multirow{2}{*}{$\begin{array}{l}\text { Time of } \\
\text { samplin } \\
\mathbf{g}\end{array}$} & \multicolumn{2}{|l|}{ Group I (pg/mL) } & \multicolumn{2}{l|}{ Group I (pg/mL) } & P value \\
\cline { 2 - 6 } & Mean \pm SD $^{\mathrm{a}}$ & $\mathbf{C V}^{\mathrm{b}}$ & Mean $\pm \mathbf{S D}^{\mathrm{a}}$ & $\mathbf{C V}^{\mathrm{b}}$ & \\
\hline T1 & $927.3 \pm 559.3$ & 60.3 & $785.7 \pm 404.1$ & 51.4 & $\mathrm{p}>0.05$ \\
\hline T2 & $1263.1 \pm 677.8$ & 53.6 & $1175.7 \pm 579.7$ & 49.3 & $\mathrm{p}>0.05$ \\
\hline T3 & $1864.5 \pm 612.7$ & 32.8 & $1521.3 \pm 600.1$ & 37.7 & $\mathrm{p}>0.05$ \\
\hline T4 & $2515.5 \pm 797.0$ & 31.6 & $1969.8 \pm 777.4$ & 39.4 & $0.028^{*}$ \\
\hline T5 & $2575.3 \pm 1118.4$ & 43.4 & $2041.5 \pm 919.9$ & 45 & 0.096 \\
\hline T6 & $1966.9 \pm 1013.8$ & 51.5 & $1708.7 \pm 769.1$ & 45 & $\mathrm{p}>0.05$ \\
\hline T4 - T1 & $1588.1 \pm 702.3$ & & $1184.0 \pm 571.8$ & & $0.037^{*}$ \\
\hline T5 - T1 & $1647.9 \pm 766.9$ & & $1255.7 \pm 753.0$ & $0.049^{*}$ \\
\hline aStandard deviation, ${ }^{\mathrm{b}}$ Coefficient of variation, ${ }^{*}$ Significant Concentration \\
\hline
\end{tabular}

Table 4: Concentrations of TNF-sR1 in plasma samples from patients of group I (on-pump roller CABG) and group II (on-pump centrifugal CABG)

Regarding IL-6, the plasma levels in patients of groups I and II were comparable up to T3 but increased at T4 and peaked at T5 (Table 5 and Figure 1C). The between-group differences in plasma IL-6 levels were statistically significant only at T5 $(\mathrm{P}=0.006)$. Between-group differences in the plasma levels of IL-6 at the various times of sampling showed that at T5 the IL-6 levels were higher in group I $(\mathrm{P}=0.010$; Table 5). Additionally, the within-group differences in plasma IL-6 levels were: group I, T5 $>\mathrm{T} 4>\mathrm{T} 6>\mathrm{T} 1=\mathrm{T} 2=\mathrm{T} 3$; group II, $\mathrm{T} 5=$ $\mathrm{T} 4>\mathrm{T} 6>\mathrm{T} 1=\mathrm{T} 2=\mathrm{T} 3$; the differences indicated were statistically significant $(\mathrm{P}<0.001)$.

\begin{tabular}{|c|c|c|c|c|c|}
\hline \multirow{2}{*}{$\begin{array}{l}\text { Time of } \\
\text { samplin } \\
\mathrm{g}\end{array}$} & \multicolumn{2}{|l|}{ Group I (pg/mL) } & \multicolumn{2}{|c|}{ Group I (pg/mL) } & \multirow[t]{2}{*}{$P$ value } \\
\hline & Mean \pm SD $^{a}$ & $\mathrm{CV}^{\mathrm{b}}$ & Mean \pm SD $^{\mathrm{a}}$ & $\mathrm{CV}^{\mathrm{b}}$ & \\
\hline T1 & $285.8 \pm 663.7$ & 232.1 & $203.5 \pm 640.8$ & 314.8 & $p>0.05$ \\
\hline $\mathrm{T} 2$ & $197.2 \pm 450.7$ & 228.5 & $152.7 \pm 508.4$ & 332.8 & $p>0.05$ \\
\hline T3 & $236.4 \pm 486.9$ & 205.9 & $200.1 \pm 471.0$ & 235.3 & $p>0.05$ \\
\hline T4 & $627.6 \pm 555.5$ & 88.5 & $427.1 \pm 437.1$ & 102.3 & 0.197 \\
\hline T5 & $1190.2 \pm 731.2$ & 61.4 & $596.4 \pm 594.7$ & 99.72 & $0.006^{*}$ \\
\hline T6 & $407.4 \pm 469.3$ & 115.1 & $333.7 \pm 421.3$ & 126.2 & $p>0.05$ \\
\hline $\mathrm{T} 4-\mathrm{T} 1$ & $341.8 \pm 435.1$ & & $223.6 \pm 324.1$ & & 0.466 \\
\hline $\mathrm{T} 5-\mathrm{T} 1$ & $904.4 \pm 740.1$ & & $392.9 \pm 593.6$ & & $0.013^{*}$ \\
\hline
\end{tabular}

Table 5: Concentrations of IL-6 in plasma samples from patients of group I (on-pump roller CABG) and group II (on-pump centrifugal CABG).

The levels of all three cytokines (MCP-1, TNF-sR and IL6) increased in the postoperative period, particularly at T4 and/or T5 in 
both groups I and II. The peaked level of cytokines in patients of group I was always higher than those of group II (T5 - T1).

\section{Discussion}

The mechanism of the IR observed in on-pump cardiac surgeries is not clearly understood [4]. The IR has been related to many proinflammatory risk factors such as trauma due to large-scale surgery, blood aspiration from the pericardial cavity, ischemia interval time and injury from reperfusion, flow of blood through ECC components, contact of blood with non-endothelial surfaces, and mechanical and electromagnetic impulses generated by pumps $[9,10]$. These factors may lead to activation of the complement system, macrophages, cytokines, fibrinolysis, coagulation and haemolysis [9,10]. Even though a large range of inflammatory mediators has been examined, there is little agreement as to witch inflammatory is most predictive of the development of organ dysfunction or which one is important clinically after on-pump CABG. Identifying a common link to the generation of IR is important and may allow future therapies [1].

In the present study we verified that both roller and centrifugal pumps increase the release of the inflammatory cytokines MCP-1, TNF-sR1 and IL- 6 after on-pump CABG in relation to preoperative levels. The increase was verified at $2 \mathrm{~h}$ and $6 \mathrm{~h}$ after surgery but return to normal levels within $24 \mathrm{~h}$, indicating that ECC stimulates IR since the beginning of the procedure. This result is in agreement with previous findings that cytokines levels increase significantly in the first hours of the postoperative period and after 24 to $48 \mathrm{~h}$ after the procedure the levels decrease [2,11-14]. Our study further confirms that ECC induces a significant IR independent of the pumping technique employed. Furthermore, use of the roller pump was associated with higher cytokine plasma levels in comparison with the centrifugal pump. Interestingly, besides studying IL-6 and TNF-sR1 we also addressed the behavior of MCP-1.

MCP-1 is a chemokine that regulates the migration of monocytes to infection sites and to atherosclerotic lesions throughout the vasculature. MCP-1 is present at various phases of the atherosclerotic process, including during the rupture of the atherosclerotic plaques in acute myocardial infarction and in the infarcted region after the ischaemic event. MCP-1 has recently been proposed as an independent prognostic marker for acute coronary syndrome [15-17]. Elucidation of the mechanism of action of this cytokine may lead to the development of pharmaceuticals that function as antagonists of MCP-1 receptors, thus providing alternative treatments for atherosclerosis. Interestingly, laboratory experiments have shown that MCP-1 is the cytokine that suffers most change when blood contacts with the non-endothelial surfaces of the ECC circuit [16,17]. It is possible that the roller pump intensifies contact of the blood with such surfaces by virtue of the constant compression of the rollers over the tubing and the consequent shearing effect. In this context we may assume that the MCP-1 levels could be higher and on-pump roller patients.

The cytokine receptor TNF-sR $\mathrm{R}_{1}$ is more stable than TNF and may serve as a valuable pro-inflammatory marker in comparative studies of ECC equipment. In the present study, differences between the preoperative (T1) levels and the postoperative (T4 and $\mathrm{T} 5$ ) concentrations of TNF-sR $\mathrm{R}_{1}$ were significantly higher $(\mathrm{P}=0.037$ and 0.049 , respectively) in patients who had been exposed to the roller pump rather than to the centrifugal pump. High levels of TNF-sR have been detected in patients who presented unfavourable evolution and mortality following acute myocardial infarction events, while elevated preoperative levels of the receptor predict a poor prognosis for cardiac surgery [18-21]. However, the clinical role of this marker in the perioperative and postoperative periods is not known and, therefore, the significance of the observed increase in TNF-sR $R_{1}$ in patients exposed to the roller pumping system is unclear.

IL- 6 is produced by a variety of cell types, including monocytes, endothelial cells and lymphocytes, and influences antigen-specific immune responses and inflammatory reactions. In the present study, the difference between the preoperative (T1) and postoperative (T5) concentrations of IL- 6 was significantly higher $(\mathrm{P}=0.013)$ in patients who had been exposed to the roller pump rather than to the centrifugal pump. This finding is in agreement with previous reports that plasma IL-6 increases significantly during the first hours after beginning of ECC [2]. Moreover, longer procedures result in more intense IR, and a direct correlation between plasma IL-6 levels and mortality following ECC has been observed [20,21].

We found that centrifugal pump had less negative effects on the IR compared to roller pumps. Accordingly, advantages of centrifugal over roller pumps has been reported by some authors, especially in procedures involving prolonged (>120 min.) ECC in which the risks of haemolysis, alterations in blood clotting, IR and perioperative and postoperative clinical complications are higher [22,23]. However, as far as shorter perfusion time of less than $120 \mathrm{~min}$, the advantages of centrifugal pumping remain controversial. In the present study, the meantime of ECC was 59.4 and 62.6, in groups I and II, respectively. However, other investigators comparing the outcomes of on-pump CABG procedures with roller or centrifugal systems have failed to show haematological or haemodynamic significant differences between patients operated on with two pumping devices [22-24]. Furthermore, a recent study verified greater number of postoperative cognitive deficits in patients submitted to on-pump centrifugal CABG [5]. The before mentioned authors did not studied cytokines profile [5,22-24].

Attempted to explain the emergence of IR in patients submitted to on-pump CABG by addressing cellular responses, plasma inflammatory mediators and components of the complement system has pursued but most of the studies have involved small numbers of patients and have showed conflicting results [9,11-13,23-25]. Moreover, these results may be somewhat dated since current ECC circuits are fabricated using up-to-date pump technology together with novel and more biocompatible materials such as heparinized tubes and nanometric thin film membranes, features that offer significant advantages independent of the pumping system employed. Although both roller and centrifugal systems have been used throughout the world for many years, controversy remains regarding the functional superiority of one system over the other. The very few previous studies that analysed IR in patients submitted to elective onpump centrifugal CABG compared to on-pump roller CABG showed conflicting results. In this context, Ashraf et al. verified greater levels of cytokines IL-1 $\beta$, IL-6, IL- 8 and TNF $\alpha$, complement component C5b-9 and neutrophil elastase in patients submitted to elective on-pump centrifugal CABG compared to on-pump roller CABG [12]. Baufreton et al. determined the concentrations of TNFa, IL-6, IL-8, adhesion molecules, complement activation complex SC5b-9 and elastase in randomized groups of patients who had been submitted to on-pump roller CABG $(n=15)$ or on-pump centrifugal CABG $(n=14)$ [13]. More intense activation of the complement and of neutrophils was observed in on-pump centrifugal CABG group. After the operation, 
however, both groups showed similar levels of IR. It is important to emphasize that, in this study, the antifibrinolytic agent aprotinin was administered to the patients during the operation, and the preoperative use of acetyl salicylic acid was not interrupted. However, Morgan et al. evaluated the pro-inflammatory markers IL-2, IL-6 and IL-8 and compared haemolysis (free plasma haemoglobin), leukocyte counting and degree of platelet and complement (C3a and C5a) activation verifying that haemolysis, platelet activation and IR were less intense on on-pump centrifugal CABG compared to on-pump roller CABG [25]. Our study, adds to the knowledge by evaluating the behavior of MCP-1 that, to the best of our knowledge, had not been previously associated with coronary surgery besides to the other cytokines (TNF-sR1 and IL-6) evaluated. Additionally, different from others, we included diabetic individuals with ventricular ejection fraction $>30 \%$, since these patients are frequent candidates for elective cardiac surgery [3].

We demonstrated that the cytokines MCP-1, TNF-sR1 and IL-6 increase after $C A B G$ in relation to preoperative levels. The higher increase was noticed on on-pump roller CABG procedures with no translation in clinical postoperative outcomes.

\section{Conclusion}

Both roller and centrifugal ECC pumping systems induced inflammatory responses in adult patients submitted to CABG as showed by increased levels of the cytokines MCP-1, TNF-sR $\mathrm{R}_{1}$ and IL-6 at 2 and $6 \mathrm{~h}$ after the procedure. Although the roller technology induced a significant increase in cytokines, there were no differences between the two groups of patients regarding clinical evolution in the postoperative period.

\section{References}

1. Hall R (2013) Identification of inflammatory mediators and their modulation by strategies for the management of the systemic inflammatory response during cardiac surgery. J Cardiothorac Vasc Anesth 27: 983-1033.

2. Moura HV, Pomerantzeff PMA, Gomes WJ (2001) Systemic inflammatory response syndrome: role of the interleukins. Rev Bras Cir Cardiovasc 16: 376-387.

3. Eagle KA, Guyton RA, Davidoff R (2004) ACC/AHA 2004 guideline update for coronary artery bypass graft surgery: a report of the American College of Cardiology; American Heart Association Task Force on Practice Guidelines (Committee to Update the 1999 Guidelines for Coronary Artery Bypass Graft Surgery). Circulation 110: e340-437.

4. Bayram H, Erer D, Iriz E, Zor MH, Gulbahar O, et al. (2012) Comparison of the effects of pulsatile cardiopulmonary bypass, non-pulsatile cardiopulmonary bypass and off-pump coronary artery bypass grafting on the inflammatory response and S-100beta protein Perfusion. 27: 56-64.

5. Holinski S, Claus B, Haeger N, Neumann K, Uebelhack R, et al. (2013) Effect of different pump heads for CPB on early cognitive outcome after coronary artery bypass surgery. Ann Thorac Cardiovasc Surg 19: 273-278.

6. Saczkowski R, Maklin M, Mesana T, Boodhwani M, Ruel M (2012) Centrifugal pump and roller pump in adult cardiac surgery: a metaanalysis of randomized controlled trials. Artif Organs 36: 668-676.

7. Melgarejo E, Medina MA, Sanchez-Jiménez F, Urdiales JL (2009) Monocyte chemoattractant protein-1: a key mediator in inflammatory processes. Int J Biochem Cell Biol 41: 998-1001.

8. Nashef SA, Roques F, Hammill BG, Peterson ED, Michel P, et al. (2002) EurpSCORE Project Group Validation of European System for Cardiac
Operative Risk Evaluation (EuroSCORE) in North American cardiac surgery. Eur J Cardiothorac Surg 22: 101-105.

9. Levy JH, Tanaka KA (2003) Inflammatory response to cardiopulmonary bypass. Ann Thorac Surg 75: S715-720.

10. Landis RC, Arrowsmith JE, Baker RA, de Somer F, Dobkowski WB, et al. (2008) Consensus statement: Defining minimal criteria for reporting the systemic inflammatory response to cardiopulmonary bypass. Heart Surg Forum 11: E316-322.

11. Morgan IS, Codispoti M, Sanger K, Mankad PS (1998) Superiority of centrifugal pump over roller pump in paediatric cardiac surgery: prospective randomised trial. Eur J Cardiothorac Surg 13: 526-532.

12. Ashraf S, Butler J, Tian Y, Cowan D, Lintin S, et al. (1998) Inflammatory mediators in adults undergoing cardiopulmonary bypass: comparison of centrifugal and roller pumps. Ann Thorac Surg 65: 480-484.

13. Baufreton C, Intrator L, Jansen PG, te Velthuis H, Le Besnerais P, et al. (1999) Inflammatory response to cardiopulmonary bypass using roller or centrifugal pumps. Ann Thorac Surg 67: 972-977.

14. Ribeiro NAM, Stolf NAG, Silva AF Jr, et al. (2004) Efeito do azul de metileno na resposta inflamatória e hemodinâmica em pacientes submetidos à cirurgia de revascularização miocardica com circulação extracorpórea. Rev Bras Cir Cardiovasc 19: 17-23.

15. de Lemos JA, Morrow DA, Blazing MA, Jarolim P, Wiviott SD, et al. (2007) Serial measurement of monocyte chemoattractant protein-1 after acute coronary syndromes: results from the A to $\mathrm{Z}$ trial. J Am Coll Cardiol 50: 2117-2124.

16. de Lemos JA, Morrow DA, Sabatine MS, Murphy SA, Gibson CM, et al. (2003) Association between plasma levels of monocyte chemoattractant protein-1 and long-term clinical outcomes in patients with acute coronary syndromes. Circulation 107: 690-695.

17. Charo IF, Ransohoff RM (2006) The many roles of chemokines and chemokine receptors in inflammation. N Engl J Med 354: 610-621.

18. Gelape CL, Sanches MD, Teixeira AL, Teixeira MM, Braulio R, et al. (2007) Preoperative plasma levels of soluble tumor necrosis factor receptor type I (sTNF-RI) predicts adverse events in cardiac surgery. Cytokine 38: 90-95.

19. Valgimigli M, Ceconi C, Malagutti P (2005) Tumor necrosis factor-alpha receptor 1 is a major predictor of mortality and new-onset heart failure in patients with acute myocardial infarction: the cytokine-activation and long-term prognosis in myocardial infarction (c-alpha) study. Circulation 111: 863-870.

20. Marano CW, Garulacan LA, Laughlin KV, Igidbashian L, Trace C, et al. (2000) Plasma concentrations of soluble tumor necrosis factor receptor I and tumor necrosis factor during cardiopulmonary bypass. Ann Thorac Surg 70: 1313-1318.

21. Wei M, Kuukasjärvi P, Laurikka J, Pehkonen E, Kaukinen S, et al. (2001) Inflammatory cytokines and soluble receptors after coronary artery bypass grafting. Cytokine 15: 223-228.

22. Moon YS, Ohtsubo S, Gomez MR, Moon JK, Nosé Y (1996) Comparison of centrifugal and roller pump hemolysis rates at low flow. Artif Organs 20: $579-581$

23. Scott DA, Silbert BS, Blyth C, O'Brien J, Santamaria J (2001) Blood loss in elective coronary artery surgery: a comparison of centrifugal versus roller pump heads during cardiopulmonary bypass. J Cardiothorac Vasc Anesth 15: 322-325.

24. Hansbro SD, Sharpe DA, Catchpole R, Welsh KR, Munsch CM, et al. (1999) Haemolysis during cardiopulmonary bypass: an in vivo comparison of standard roller pumps, nonocclusive roller pumps and centrifugal pumps. Perfusion 14: 3-10.

25. Morgan IS, Codispoti M, Sanger K, Mankad PS (1998) Superiority of centrifugal pump over roller pump in paediatric cardiac surgery: prospective randomised trial. Eur J Cardiothorac Surg 13: 526-532. 